Universidad de Lima

Facultad de Derecho

Carrera de Derecho

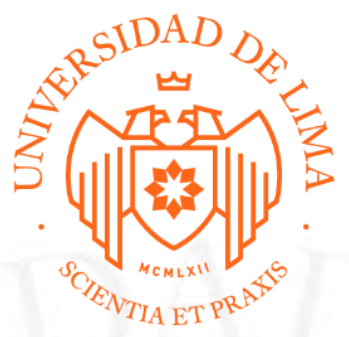

\title{
ARBITRAJE: "ARBITRAJE
}

\section{INSTITUCIONAL" Y ADMINISTRATIVO: "PROTECCIÓN AL CONSUMIDOR"}

Trabajo de suficiencia profesional para optar el Título Profesional de Abogada

\author{
Sandra Kely Bonet Villegas
}

Código 20091384

Lima - Perú 
ARBITRAJE: "ARBITRAJE INSTITUCIONAL"

Materia: Arbitraje Institucional

$\mathrm{N}^{\mathrm{o}}$ de Expediente: DE-ARBIT0091

ADMINISTRATIVO: "PROTECCIÓN AL CONSUMIDOR"

Materia: Protección al consumidor

$\mathrm{N}^{\mathrm{o}}$ de Expediente: DE-INDEC0417 